\title{
Morbo, género y terror: \\ la construcción del nihilismo ruso en la prensa liberal española de fin de siglo
}

\author{
Sandra Pujals Ramírez \\ Departamento de Historia \\ Universidad de Puerto Rico \\ spuprrp@gmail.com
}

Recibido: $27 / 03 / 2014$

Aceptado: 15/06/2014

\begin{abstract}
RESUMEN
Este ensayo discute reportajes de prensa y textos académicos publicados en España a raíz del asesinato del zar Alejandro II en 1881, proponiendo ejemplos del uso del nihilismo ruso como metáfora y plataforma de debate para temas locales relacionados con género, nación, modernización y progreso. El trabajo señala la forma en que temas pertinentes a la ola terrorista revolucionaria que azotaba a Rusia, disfrazaban una discusión sobre asuntos nacionales españoles. El artículo puntualiza, además, la utilidad política y social del asunto para una España en pleno proceso de Restauración monárquica después de un corto pero dramático período revolucionario. La investigación identifica comentarios en torno a elementos polémicos del debate sobre el proceso de modernización social y política en España, tales como la educación superior para la mujer, la identidad nacional y la nación en el contexto europeo, disimulados en la narrativa sobre eventos en Rusia. Más allá de propuestas teóricas, el trabajo propone ejemplos concretos de una interacción cultural transnacional, al apuntar la manera en que una articulación quimérica sobre un país extranjero puede jugar un papel en el montaje distanciado del imaginario cultural autóctono.
\end{abstract}

Palabras claves: España, fin de siglo, nihilismo ruso, terrorismo, belleza, sexualidad y género, ideales burgueses, modernidad, prensa, imaginario nacional, transnacionalismo.

\section{Lust, Gender, and Terror: The Construction of Russian Nihilism in Spain's fin de siécle liberal press}

\begin{abstract}
This essay discusses the construction of a cultural vision of Russian nihilism in the Spanish liberal press following the assassination of Alexander II in 1881, identifying the codified metaphoric context of texts and suggesting their possible political and social applicability to the local panorama of the Restoration period. The article points out the ways in which reports of Russian revolutionary events masqueraded a discussion of national issues and contemporary debates concerning political and social modernization, gender, women's access to higher education, national identity, and Spain's place in the European context. The exploration highlights the malleable boundaries separating the press and the literary realm in the late nineteenth century, and provides a transnational panorama beyond theoretic postulates of how the depictions of foreign circumstances, issues, and another country's people and politics may have played a role in the distanced articulation of autochthonous cultural imaginaries.
\end{abstract}


Key words: Spanish fin de siècle, Russian nihilism, terrorism, nigiliska, nineteenth century press, gender and beauty, gender and sexuality, Spanish modernity, bourgeois ideals, national imaginaries, transnationalism.

Referencia normalizada: Pujals Ramírez, S. (2013). "Morbo, género y terror: la construcción del nihilismo ruso en la prensa liberal española de fin de siglo". Revista de Historia Contemporánea, Vol.:36 páginas: $215-238$.

Sumario: Introducción. 1. Consideraciones historiográficas y metodológicas 1.1. Los debates intelectuales en torno a la modernización social y política en la España de fin de siglo: Rusia como metáfora. 2. El nihilismo ruso: de fenómeno político a icono cultural de fin de siglo 2.1 El nihilismo ruso: una "leyenda moderna". 2.2 Rusia y el nihilismo en la España de la Restauración 2.3 Rusia y el nihilismo en la prensa intelectual española de fin de siglo. 2.4 La bella y la bestia: género y modernidad en los reportajes sobre el nihilismo ruso. 3. Comentarios finales. 4. Referencias bibliográficas.

\section{Introducción}

El primero de marzo de 1881 moría a manos de un grupo terrorista, el zar Alejandro II de Rusia. El asesinato, en el cual dos mujeres compartían liderato con sus compañeros nihilistas, era sólo un eslabón en una cadena de atentados y violencia política que sacudía al país desde la década anterior. ${ }^{1}$ No obstante, el evento serviría para robustecer la construcción de una simbología de género fundamentada en los elementos de valentía, sacrificio y pasión de solapado erotismo, encarnados en un personaje femenino trágico, heroico, misterioso y aventurero. De esta forma nacía el estereotipo de la estoica nihilista rusa como símbolo de las más excelsas virtudes femeninas y manifestación plena del espíritu de una nueva era. Entregada totalmente a la lucha por la libertad, y rechazando las vanidades propias de su sexo en aras de la redención de su pueblo esclavizado por el despotismo, este personaje se popularizaría en novelas y obras de teatro europeas y estadounidenses de fin de siglo. ${ }^{2}$

La popularidad y vigencia del paradigma heroico de la nihilista rusa en una cultura fascinada a la vez que avasallada por una modernización intensa, convertiría también

1 VENTURI, Franco: Roots of Revolution. A History of Populist and Socialist Movements in Nineteenth Century Russia, New York, Alfred A. Knoff, 1960; YARMOLINSKY, Avrahm: Road to Revolution: A Century of Russian Radicalism, London, Cassell Books, 1957. El término "nihilismo" fue acuñado originalmente en la década de 1860 por Ivan Turgénev para identificar a uno de los personajes de su obra Padres e hijos. Al ser indicativo de una actitud de "total negación" del orden social, político y cultural, su significado estaba enmarcado en un contexto filosófico. En épocas recientes, los términos "nihilismo" ("político", "moral" o "existencial"), "terrorismo" y "violencia política" han sido protagonistas de una serie de debates en torno a aspectos filosóficos y semánticos. Ver: HOFFMAN, Bruce: Inside Terrorism, New York, Columbia University Press, 1998. No obstante, dichas consideraciones no tienen espacio en la discusión presente, en la cual se utiliza "nihilismo" como sinónimo de "terrorismo" según aparecía en la prensa y la literatura de la época.

2 Para una corta discusión en torno al nihilismo ruso como fenómeno cultural y literario de alcance internacional, ver: MARKS, Steven G.: How Russia Shaped the Modern World: From Art to Anti-Semitism, Ballet to Bolshevism, Princeton (New Jersey), Princeton University Press, 2004. Varias obras también discuten el contexto cultural de este tipo de acción política: BURLEIGH, Michael: Blood and Rage: A Cultural History of Terrorism, New York, Harper Collins Publishers, 2008; HAUNER, Milan, "Terrorism and Heroism: The Assassination of Reinhard Heydrich," World Policy Journal 24, no. 2 (Summer, 2007), pp. 85-89. 
al terrorismo nihilista ruso en metáfora y vehículo para la discusión y difusión de visiones sobre género, progreso y nación, especialmente en la prensa liberal europea de la época. La imagen idealizada, colmada de paradojas, iría a la vez reforzada por la realidad pregonada en relatos periodísticos que parecían muchas veces validar los estereotipos quiméricos. No obstante, a pesar de que algunos detalles se repetían como denominador común, elementos subliminalmente relacionados con el espíritu autóctono y la experiencia nacional definían también diferencias y perspectivas. De acuerdo con la prensa estadounidense, por ejemplo, los artículos sobre el nihilismo ruso en los diarios franceses sobresalían por ser los más piquant y "subidos de tono", particularmente al ensalzar la "fuerza explosiva" de las revolucionarias, lo cual parecía verificar el gusto por la sensualidad que identificaba a los franceses en la cultura anglo-sajona. ${ }^{3}$ En Gran Bretaña, el tema se analizaba más bien por medio del prisma del radicalismo irlandés, por lo que las perspectivas tendían a rechazar las apologías al prototipo nihilista. ${ }^{4}$ Finalmente, en los Estados Unidos, el terrorismo ruso reforzaba subliminalmente los debates en torno a los valores del sistema democrático, para una nación en plena recuperación social y política después de una sangrienta guerra civil. En este caso, las referencias a la "esclavitud", la "servidumbre" y las "cadenas", además de directas comparaciones con la propia experiencia de guerra civil, colorearan las discusiones sobre la lucha por la libertad de los nihilistas. ${ }^{5}$

Las posturas revolucionarias de los nihilistas también inducían a la reflexión, particularmente en Europa, donde el modelo de monarquía constitucional se perfilaba como el arquetipo de un sistema "democrático" y "moderno". Como método de acción revolucionaria, la subversiva alternativa rusa pronto pasaría a ser un artículo de exportación, transformándolo así en paradigma de alcance internacional y significado transnacional. ${ }^{6} \mathrm{La}$ insistencia de los terroristas rusos en identificar su movimiento con las consignas cristianas de entrega, sacrifico y martirio, impulsarían el debate sobre los límites del radicalismo y el extremismo como opción política factible. ${ }^{7}$ El espacio público, siempre presto a organizar perspectivas en respuesta a asuntos y eventos, jugaría un papel significativo en este caso también. Rusia, su terrorismo nihilista y

\footnotetext{
3 New York Herald, Nueva York, 4/04/1881, p. 4. El adjetivo "francés" servía muchas veces para identificar lo erótico, como, por ejemplo, en el caso de las postales pornográficas, las cuales se denominaban "French postcards" sin importar su lugar origen. En la literatura naturalista española de toque erótico en esta época, Paris aparecía algunas veces como elemento de contenido metafórico, como, por ejemplo, en la novela Venus granadina de Remigio Vega Armentero: LISSORGUES, Yvan: Realismo y naturalismo en la España de la segunda mitad del siglo XIX, Barcelona, Anthropos, 1988, p. 190.

4 "Nihilist Stepniak", Cincinnati Commercial Tribune, Cincinnati (Ohio), vol. XLVII, iss. 124, 30/01/1888, p. 3 .

5 St. Louis Republic, St. Louis (Missouri), vol. LXXXII, iss. 21830, 19/03/1890, p. 4; The Sun, Nueva York, vol. CVII, iss. 33, 24/06/1890; "George Kennan's Graphic Story”, Springfield Republican, Springfield (Pennsylvania), 26/10/1890, p.1; "Russian Refugees", Boston Daily Adviser, Boston, vol. 151, iss. 24399, 08/02/1888; "Future of Russia", Chicago Herald, Chicago, 25/01/1890, p.10.

6 MARKS, Steven: How Russia Shaped the Modern World, pp. 1-36. El "trasnacionalismo" como concepto se diferencia del "internacionalismo" por el aspecto de transformación y cambio que proporciona un elemento a las costumbres nacionales en otro lugar o región.

7 CHALIAND, Gerald et al (eds.): History of Terrorism and Guerrilla Warfare: From Antiquity to AlQaeda, Berkeley, University of California Press, 2007; AVILÉS FARRÉ, Juan: La daga y la dinamita: Los anarquistas y el nacimiento del terrorismo, Barcelona, Tousquets, 2013.
} 
sus revolucionarios se convertirían en otra oportunidad para definir de forma aun más precisa, una plataforma concreta para el confuso y contradictorio conjunto normativo que los historiadores identifican con el término de "modernidad" decimonónica. ${ }^{8} \mathrm{De}$ aquí que la construcción de prototipos sobre ese "otro" ruso y sus circunstancias políticas y sociales sirva para evaluar la transcendencia de aspectos transnacionales en la definición de elementos culturales como género e identidad nacional. ${ }^{9}$

Este ensayo discute varios reportajes de prensa y textos académicos publicados en España a raíz del asesinato del Alejandro II, proponiendo ejemplos del uso del nihilismo ruso y, en particular, de su arquetipo femenino como espacio metafórico y plataforma de debate para temas locales relacionados con género, nación y modernización política y social. El mismo analiza los comentarios y noticias de dos diarios liberales sobresalientes, La Vanguardia y El Constitucional, así como las perspectivas resumidas en dos libros de destacados intelectuales, publicados durante esa época. La discusión parte de la pregunta en torno a la construcción de una visión sobre el terrorismo ruso en la prensa liberal española, particularmente en relación a la propuesta extremista e iconoclasta que el movimiento proponía para la participación femenina en la esfera pública y política. El trabajo señala la forma en que temas rusos disfrazaban el análisis de asuntos nacionales, y puntualiza la utilidad política de esta estrategia discursiva para una España en pleno proceso de Restauración monárquica después de un corto pero dramático período revolucionario. ${ }^{10}$

La presentación ofrece, además, un ángulo transnacional para la construcción de visiones culturales locales, como muestra del complejo montaje de elementos contradictorios y anacrónicos que informan este tipo de proceso. En general, el ensayo sugiere el uso de aspectos internacionales en la definición de un panorama de lo autóctono, así como la forma en que estereotipos, experiencia, actitudes colectivas y gustos populares se funden en el colorido rompecabezas que conocemos como "cultura". Los ejemplos de la prensa intelectual española de fin de siglo demuestran que, a pesar de discutir temas relativos a Rusia, las propuestas en torno a este "otro" extranjero y lejano escondían semejanzas con la situación local, convirtiendo así a España en una Rusia en potencia. De aquí que las perspectivas esbozadas aportaran ese aspecto de holograma o realidad virtual, una imagen unidimensional pero viva en la que el entorno ruso, aparentemente observado desde España, servía a la vez de reflejo para la historia reciente y el momento presente de la propia nación española.

8 BERIAIN, Josetxo: Modernidades en disputa, Barcelona, Anthropos, 2005; GIROLA, Lidia y OLVERA, Margarita: Modernidades: Narrativas, mitos e imaginarios. Barcelona, Anthropos, 2007; KOZLAREK, Oliver: "Teoría y método para una crítica comparada de la modernidad", Nueva Sociedad, Núm. 194, pp. 38-51.

9 PORTES, Alejandro, GUARNIZO, Luis E., LANDOLT, Patricia (eds.): "The study of transnationalism: pitfalls and promises of an emergent research field", Ethnic and Racial Studies, Vol. 22, Núm. 2 (1999), pp. 217-237.

10 DE LA FUENTE, Gregorio: Los revolucionarios de 1868: élites y poder en la España liberal. Madrid, Marcial Pons, 2000; DE LA FUENTE, Gregorio: “Actores y causas de la revolución de 1868”, en Rafael García Serrano, España, 1868-1874. Nuevos enfoques sobre el Sexenio Democrático, Valladolid, Junta de Castilla y León, 2002; FONTANA, Josep: La época del liberalismo, en Josep Fontana y Ramón Villares (eds.), Historia de España, Barcelona, Crítica/Marcial Pons, 2007, vol. 6. 
El trabajo constituye una muestra concreta más allá de propuestas teóricas, de la manera en que una articulación quimérica sobre un país extranjero puede jugar un papel en el montaje distanciado del imaginario autóctono. ${ }^{11}$ De acuerdo con las perspectivas políticas del autor, el caso de Rusia permitía examinar de cerca las posibles consecuencias de la falta de una evolución política progresista en épocas de fervor revolucionario, como la que España había atravesado pocos años antes. Por otro lado, Rusia también ofrecía una prueba fehaciente de los peligros de apresurarse a abrazar proyectos políticos y sociales modernizadores como la propuesta liberal en torno a la participación de la mujer en el entorno público, especialmente su derecho a una educación universitaria. Muchas de las nihilistas tenían una experiencia universitaria, lo cual se explicaba como detonante y antesala para su adoctrinamiento político así como para la irreverencia que mostraban ante los preceptos y la autoridad. El entorno universitario también inducía a un comportamiento sexual desordenado, al servir de lugar de encuentro libre para jóvenes de ambos sexos. De aquí que el regicidio de Alejandro II y el movimiento revolucionario conectado con el evento, se convirtieran en ejemplo extremo y advertencia comprobada de los riesgos de confundir la modernización política y social con el radicalismo, y la democratización institucional con el libertinaje.

\section{Consideraciones historiográficas y metodológicas}

\subsection{Los debates intelectuales en torno a la modernización social y política en la España de fin de siglo: Rusia como metáfora}

Este trabajo presenta un ejemplo de contextualización para un momento histórico crucial en España, dentro del cual se debatía la trayectoria misma de la era posrevolucionaria de la Restauración. ${ }^{12}$ En estos debates, parte esencial del proyecto de modernización y liberalismo que definiría el fin de siglo decimonónico, la esfera pública, más que el entorno político, sobresaldría como artífice y arquitecto del proceso. ${ }^{13}$ Los textos estudiados sugieren primeramente la construcción de un estereotipo sobre

11 Véase GUIDOTTI-HERNÁNDEZ, Nicole: Unspeakable Violence: Remapping US and Mexican National Imaginaries, Durham, Duke Univ. Press, 2011; HSIAO, Li Chun (ed.): This Shipwreck of Fragments: Historical Memory, Imaginary Identities, and Postcolonial Geography in Caribbean Culture and Literature, Newcastle upon Tyne, Cambridge Scholars Publishing, 2009; SAN MIGUEL, Pedro: The Imagined Island: History, Identity, and Utopia in Hispaniola, Chapel Hill, Univ. Of North Carolina Press, 1997; FOX, E. Inman: La invención de España: Nacionalismo liberal e identidad nacional, Madrid, Cátedra, 1998; AYNES, Jean René y SEBASTIÁN, Javier Fernández (eds.): La imagen de Francia en España (1808-1850), Bilbao, Universidad del País Vasco, 1997. No obstante, la idea de que un "otro" nacional imaginario pueda servir como plataforma para la construcción de otro espacio o identidad nacional no se incluye por lo regular como alternativa.

12 Para una discusión muy acertada sobre la necesidad de una contextualización histórica integrada al análisis literario, ver: LABANYI, Jo: "Relocating Difference: Cultural History and Modernity in Late $19^{\text {th }}$ Century Spain,” en Bradley S. EPPS y Luis FERNÁNDEZ CIFUENTES (eds.): Beyond Spain, Lewisburg (Pennsylvania), Bucknell University Press, 2005, pp. 170-79.

13 HABERMAS, Jürgen: The Structural Transformation of the Public Sphere: An Inquiry Into a Category of Bourgeois Society, Cambridge (RU), Polity Press, 1989. 
Rusia, su sistema político, su carácter nacional y particularmente su gente, bajo un esquema de un otro desplazado, "oriental" y diferente a Occidente, que servía a la vez para ubicar solapadamente a España dentro de la comunidad de naciones "modernas" de Europa.

Por otro lado, tanto los reportajes como los textos parecen haber funcionado también como foro virtual, aunque unilateral, para la discusión de asuntos específicamente relacionados con la situación social y política de España, que nada tenían que ver con Rusia ni con los eventos que se informaban. Detrás de una estratégica narrativa distanciada sobre un país lejano y aparentemente diferente se despuntaban los elementos de debates españoles contemporáneos que, sin referirse directamente a la experiencia local, podían ser identificados como propios por el lector. Entrelazados entre observaciones sobre la vida y la política despótica de aquel país se ocultaban planteamientos sobre la nación, la participación social y política de la mujer y su sexualidad, además de una serie de juicios estéticos sobre la belleza femenina, y su potencial transgresivo. Por ejemplo, la discusión sobre las terroristas servía a la vez de plataforma para subrayar los peligros de una educación superior para la mujer más allá del apropiado a "su naturaleza", uno de los caldeados debates de la primera década del período de la Restauración en vísperas del Primer Congreso Pedagógico de $1882 .{ }^{14}$

Respondiendo a una cultura popular fascinada con el melodrama de folletín, el sensacionalismo y la novela rosa, así como a la particularidad cultural española del cotilleo morboso, ${ }^{15}$ las discusiones intelectuales sobre el tema se desarrollaban en un escenario romántico de fogosas pasiones con sutiles insinuaciones eróticas, en las que muchas veces la estrella de la trama era una joven e indefensa nihilista con pistola en mano. Unas veces bella y aristocrática, cuando no fea y plebeya, de acuerdo con la perspectiva clasista de la publicación o el autor, el melodrama de pasión, engaño, sed de justicia, venganza o retribución por el honor perdido pueden haber aportado estereotipos culturales confusos de género y directrices contradictorias de comportamiento para la mujer española. De esta manera se señalaba el heroísmo de las valientes revolucionarias enfrentadas a la violencia zarista, a la vez que se sugerían las

14 FLECHA GARCÍA, Consuelo: Las primeras universitarias en España, Madrid, Narcea, 1996; FLECHA GARCÍA, Consuelo: Las mujeres en la legislación educativa española. Enseñanza primaria y normal en los siglos XVIII y XIX, Sevilla, Gihus, 1997; SAN ROMÁN GAGO, Sonsoles: Las primeras maestras. Los orígenes del proceso de feminización docente en España, Barcelona, Ariel, 1998; HERAS, Pilar y VILANOU, Conrad (eds.): Pedagogía amb veu de dones, Barcelona, Facultat de Pedagogía, 1999; BALLARIN, Pilar: La educación de las mujeres en la España contemporánea. Siglos XIX y XX, Madrid, Síntesis, 2001.

15 El cotilleo de matiz subido y/o morboso como elemento cultural decimonónico ha recibido poca atención como elemento representativo de cultura popular del siglo XIX en España. No obstante, existe un análisis epistemológico de la evolución del término "morbo" de un adjetivo referente a la muerte a su contextualización erótica actual: LEMA, María: "El morbo: ¿sólo una atracción malsana? Análisis de una conceptualización en dos culturas", Romanica.doc, Czasopismo doktorantów Instytutis Filologii Romanskiej: num. 1(2), 2011, pp. 1-12, disponible en línea: www.romdoc.amu.edu.pl/lema.html. Su valor también ha sido señalado como aspecto cultural de la España moderna, en especial en relación con la prensa del corazón y la cultura homosexual contemporánea: IMBERT, Gérard: Los escenarios de la violencia: conductas anómicas y orden social en la España actual, Madrid, Icario Editorial, 1992, pp. 117-121; PERCEVAL, José María: Nacionalismos, xenofobia y racismo en la comunicación, Madrid, Paidos Ibérica, 1995. 
diferencias entre la realidad política rusa y la española, por medio de un esquema ideológico supuestamente progresista, que solapadamente servía para proteger las estructuras de poder y dominio masculino.

\section{El nihilismo ruso: de fenómeno político a icono cultural de fin de siglo}

\subsection{El nihilismo ruso: una "leyenda moderna"}

A pesar de que el movimiento revolucionario clandestino en Rusia llevaba operando en Rusia desde la década anterior, su aparición en la escena internacional se daría de lleno en 1877, cuando una joven de nombre Vera Zasulich se enfrentó ante el poderoso y pavoroso coronel Trépoff, Gobernador de San Petersburgo, empuñando una pistola. La meta de Zasulich aparentemente era vengar el honor de uno de sus compañeros revolucionarios, quien había sufrido una terrible golpiza a manos de Trépoff después de su captura. El fallido atentado llevaría a la joven y menuda Zasulich ante los juzgados, en un juicio de gran repercusión en la esfera internacional. Jurídicamente, el caso daba la oportunidad de evaluar aspectos políticos y legales del sistema zarista, como, por ejemplo, la naturaleza violenta y desfachatada del gobierno al tratar a sus súbditos. ${ }^{16}$ El espacio también servía para la construcción de una alegoría subliminal en torno a la lucha por los derechos en Rusia, con una valerosa Zasulich como víctima y símbolo del colectivo, ante el despótico imperio representado por Trépoff. Valentía, entrega, pasión y sed de justicia identificaban a esta muchacha, obligada a responder violentamente en el nombre de todos los rusos, a la afrenta y la esclavitud del yugo zarista.

Aparte de su valor metafórico, y lejos de ser un acto fortuito, el atentado era realmente parte de un plan de un grupo terrorista al que Zasulich pertenecía, aunque la joven había decidido adelantarse y actuar por su cuenta. ${ }^{17}$ No obstante, la defensa logró convencer no solo a una población exaltada por la constante discusión pública sobre el juicio, sino a un sistema judicial inaugurado recientemente como resultado de las reformas de Alejandro II. La sentencia a su favor convertiría a Zasulich en icono del radicalismo ruso de la noche a la mañana. Bautizada por algunos de sus compañeros como el "ángel vengador", la menuda joven serviría también como fundamento para el modelo de ética, entrega y sacrificio que distinguiría a los revolucionarios rusos en la cultura popular de fin de siglo tanto en Europa como en los Estados Unidos.

A partir del suceso de Zasulich, se produjo una ola de terror contra las autoridades imperiales, seguida por una embestida represiva por parte del gobierno ruso. La

16 La más reciente discusión del juicio de Zasulich la ofrece uno de los más importantes historiadores estadounidense, Richard Pipes. Ver: PIPES, Richard: “The trial of Vera Z.", Russian History, Vol. 37 (2010).

17 Hasta hace unos años, la historiografía tradicional insistía en la inocencia de Zasulich, apuntando que la joven había actuado de forma efusiva a causa de su indignación ante el abuso del jefe de la policía zarista en San Petersburgo. Ver: BERGMAN, Jay: Vera Zasulich. A Biography, Stanford (California), Stanford University Press, 1983. Una de las investigaciones más recientes, sin embargo, ha identificado a Zasulich como parte de un grupo radical en Ucrania que entonces preparaba dos asesinatos, para lo cual Zasulich se había trasladado a la capital rusa con otra compañera. El libro también sugiere que la policía encubrió la relación de Zasulich con grupo terrorista. SILJAK, Ana: Angel of Vengence: The Girl Who Shot the Governor of St. Petersburg and Sparked the Age of Assassination, New York, St. Martin's Press, 2008. 
violenta respuesta del régimen traería además la internacionalización del movimiento revolucionario, al establecerse en varias capitales europeas, comunidades de nihilistas emigrados que promulgaban los excesos del zarismo a una Europa afanada en su proyecto de modernización política. Como resultado de las actividades de estos exiliados, se popularizaron también las apariciones públicas y las obras autobiográficas de algunos miembros del movimiento, en las que la pasión y la aventura iban de la mano de las acciones políticas. Algunas de éstas, tales como las memorias de Stepniak Kravschinskii, Sofia Kovalevskaya y Vera Figner, se destacarían como auténticos best sellers de su época. Se cuajaba, pues, de lleno un estereotipo heroico, en el que la pasión, el fanatismo ciego y la entrega sin medida a la empresa terrorista convertirían a este paradigma en una auténtica y reconocida "leyenda moderna". ${ }^{18}$

El terrorismo nihilista ruso y su prototipo femenino también cobraron importancia como referente del momento político y social en la ficción, tanto con respecto a los ideales democráticos como a las propuestas feministas, hasta convertirse en verdaderos iconos de la cultura popular de fin de siglo. Algunas obras de ficción, por ejemplo, utilizaron el paradigma de la nigiliska rusa por su aspecto melodramático y su seductora mezcla de sed de venganza en defensa del honor, entrega y aventura. La mayoría de éstas otorgaba el papel principal a una mujer dispuesta a explotar las artes femeninas de seducción para fines políticos honorables. Una de las primeras del género literario, la poco exitosa pero profética obra de Oscar Wilde, Vera o los nihilistas, vaticinaba el regicidio de Alejandro II un año antes del evento. ${ }^{19}$ Varias obras del astro de la novela rosa y autora favorita de la Reina Victoria, Marie Corelli, así como Narka, la nihilista de Kathleen O'Meara (1887), La princesa nihilista de Louise Gagneur (1881) y By Order of the Czar: The Tragic Story of Anna Klosstou, Queen of the Ghetto de Joseph Hatton (1893) incluían a la nihilista como protagonista y heroína. Obras de reconocidos autores de la época como Michael Strogoff: A Courier of the Czar de Jules Verne (1877) y una aventura siberiana de George Alfred Heanty titulada Condemned as a Nihilist: A Story of Escape From Siberia (1893), además combinaban la narrativa heróica y melodramática con episodios de aventura en exóticos parajes, lo cual consiguió convertir el tema en uno muy popular entre los lectores de ambos sexos.

Para la década de 1890 , su inclusión y popularidad como tema teatral consagraría finalmente al nihilismo como mito moderno de fin de siglo. Por ejemplo, el atractivo melodramático de sutil tonalidad erótica lo convirtieron en leit motif de una popular obra de teatro estadounidense de Henry Grattan Donelly, Darkest Russia, estrenada en Philadelphia en 1894. ${ }^{20}$ Otra obra, no menos controversial aunque de mucho más renombre internacional resulta Fedora de Victoriene Sardou, escrita para Sarah Bernhardt en 1882, un año después del asesinato de Alejandro II. ${ }^{21}$ La trama incluía algunos de los elementos icónicos que representaban el melodrama de temática rusa, con Fedo-

18 “Fanatismo nihilista”, La Vanguardia, Barcelona, 26-01-1885, p. 5.

19 Para un análisis literario de la obra y sus componentes, ver: BUCKLER, Julie A.: Imitations of Life: Two Centuries of Melodrama in Russia, Durham (North Carolina), Duke University Press, 2001.

20 "Object to Darkest Russia: Protests Against the Production of Grattan Donnelly's New Play", The New York Times, Nueva York, 19-07-1893.

21 "Striking Events in Paris: Bernhardt's Triumph in Sardou's New Piece 'Fedora'", The New York Times, Nueva York, 5-01-1883. 
ra Romanoff, la hermosa princesa entregada a la venganza por la muerte de su amante, un asesinato misterioso y un falso complot terrorista. Aunque mucho menos política, la obra retenía el aspecto erótico que caracterizaba el sub-texto del género novelesco nihilista, así como las insinuaciones sobre la naturaleza contradictoria y emotiva del carácter femenino, representados magistralmente por Bernhardt. La obra también convertiría un elemento del vestuario de la actriz en el complemento atrevido por excelencia de la moda para las próximas décadas. Bautizado con el nombre de "sombrero fedora", el accesorio de aspecto parco y masculino sería primordialmente representativo de una moda de toque feminista en la última década decimonónica, aunque luego pasaría a ser prenda masculina que identificaría a otros grupos transgresores como los inmigrantes judíos ortodoxos o los mafiosos.

De forma similar en la que la cultura radical francesa inmortalizó el ideal femenino como símbolo y personificación del espíritu revolucionario, el teatro y la literatura lograron concertar una sutil conexión entre la terrorista rusa y los valores sublimes de la lucha por la libertad y los derechos. Sus elementos característicos -la exaltación de un carácter implacable, el afán de independencia, su valentía y fortaleza- se convirtieron en una fórmula alegórica para alimentar sensuales fantasías aventureras, tanto en el público masculino, como del femenino. La fama del género también convertiría a este prototipo atractivo a la vez que tenebroso, en vehículo popular y prisma para entender la ansiedad desenfrenada producida por una época de cambio social y político caótico e intenso. ${ }^{22}$ De aquí que estos estereotipos pasaran a informar además discusiones y debates en el entorno intelectual, al tratarse de aspectos idealizados y emotivos con un grave potencial de seducir e inducir política y socialmente a la transgresión.

\subsection{Rusia y el nihilismo en la España de la Restauración}

A pesar de que la interacción, tanto cultural como política, entre Rusia y España databa de siglos anteriores, su relación en términos de visiones políticas radicales se había consolidado a lo largo de la primera mitad del siglo XIX. ${ }^{23}$ Para la primera década de la Restauración monárquica, la controvertida propuesta nihilista rusa irrumpiría en el ámbito intelectual de España, particularmente en los círculos republicanos, gracias a la presencia de algunas figuras extranjeras relacionadas al movimiento. Dos visitantes del imperio ruso ayudaron a moldear la opinión pública en algunos espacios intelectuales y culturales del país. El primero de éstos, José Leonard y Bertholet, revolucionario, humanista y educador polaco, quien se había exiliado en España después

22 Ver, por ejemplo, la discusión sobre aspectos psicológicos en la colección sobre la cultura burguesa victoriana de Peter Gay, y en particular uno de sus volúmenes: GAY, Peter: Pleasure Wars: The Bourgeois Experience: From Victoria to Freud, New York, W.W. Norton \& Company, 1999.

23 STITES, Richard: "Decembrists with a Spanish Accent," Kritika: Explorations in Russian and Eurasian History 12, no.1 (Winter 2011), pp. 5-23; NECHKINA, M.V.: "Revoliutsiia na podobie ispanskoi," Katorga $i$ ssylka, no. 10 (1931), pp. 3-40; DODOLEV, M.A.: "Russia and the Spanish Revolution, 1820-1823," Russian Studies in History, vol. 8, no. 3 (Winter 1969-70); DE MADARIAGA, Isabel: "Spain and the Decembrists," European Review 3, no. 2 (1973), pp. 141-56; RABOW-EDLING, Susanna: "The Decembrist Movement and the Spanish Constitution of 1812," Historia Constitucional, Revista electrónica, no. 13 (septiembre 2012), pp. 143-61, www.historiaconstitucional.com: http:/www.redalyc.org/articulo.oa?id=259027585007 (consultado 26/VI/2014) 
de haber jugado un papel en la revuelta polaca de 1863 en contra del régimen zarista y más tarde, en la Revolución española de 1868. A raíz del incremento del interés público por los temas rusos, Leonard dictó una conferencia titulada "El estado actual de Rusia" en El Fomento de las Artes, un reconocido club de la élite liberal republicana de Madrid, celebrada en febrero de $1880 .{ }^{24}$ Poco después, abandonaría España para trasladarse a Nicaragua, donde fungió como Director de un instituto jesuita y como maestro del aclamado poeta y pensador Rubén Darío, aunque también se le reconoce como fundador de logias masónicas en las ciudades principales del país. ${ }^{25}$

Un segundo visitante, probablemente más influyente en los círculos intelectuales españoles, fue un revolucionario de extracción judía, Isaac Pavlovsky, quien llegó a España desde Francia en 1884, después de haber logrado escapar de una prisión en Rusia. Gracias a su relación con la más alta estirpe literaria de Rusia por su matrimonio con la sobrina de la viuda del famoso poeta Alexander Púshkin, Pavlovsky había conseguido entablar amistad con grandes literatos del calibre de Antón Chéjov e Ivan Turgénev. Este último le proporcionó una carta de presentación, con la que Pavlovsky logró conectarse con varias personalidades literarias del fin de siglo español tales como Benito Pérez Galdós, Emilia Pardo Bazán y Narcís Oller, quien tradujo varios artículos del antiguo nihilista para La Ilustració Catalana. ${ }^{26}$ De firme linaje revolucionario, Pavlovsky ya se había distinguido en Paris por el recuento aventurero de su experiencia en una cárcel zarista y su triunfal evasión, publicada en Le Temps en 1880. Esta fugaz fama también lo convertirían más tarde en prototipo protagónico, aunque no necesariamente heroico, para el personaje masculino en la novela autobiográfica Nigiliska (1892) de Sofía Kovalevskaya. ${ }^{27}$ Pavlovsky regresó a Rusia en 1888, donde se dedicó a promover la cultura y la literatura española además de publicar una obra sobre su experiencia en España entre 1884 y $1885 .{ }^{28}$ Su aportación como puente y canal de comunicación entre la elite literaria rusa y la nueva generación de novelistas españoles ha sido señalada como fundamento significativo en la definición de las estructuras narrativas modernistas del emblemático movimiento realista español de la "Generación del ' 98 ". ${ }^{29}$

24 Sobre El Fomento de las Artes, ver el primer capítulo de El proletariado militante (Memorias de un internacionalista) de un reconocido socialista Anselmo Lorenzo, publicadas en 1901, disponibles en línea (verificado el 02/06/2013: http:/www.antorcha.net/biblioteca_virtual/historia/proletariado/1.html

25 Las fuentes para Leonard son escasas, aunque algunas reconoce su influencia como maestro de Rubén Darío: URBANSKI, Edmund Stephen: "El Doctor José Leonard: El maestro de Rubén Darío y sus actividades culturales Franco-Españolas-Latinoamericanas," Anuario de Estudios Centroamericanos, no. 1 (1974): 3346; WHISNANT, David E.: "Ruben Dario as a Focal Cultural Figure in Nicaragua: The Ideological Uses of Cultural Capital," Latin American Research Review, 27, no. 3 (1992), pp. 7-49.

26 Además de la traducción de varios artículos, Oller escribió el prólogo para la traducción al español de un artículo de Pavlovsky sobre la experiencia de prisión política "En cellule, memoires d'un nihilist", publicado en 1886 para La Ilustració Catalana, bajo el título de "Memories d'un nihilista".

27 Al parecer, Pavlovsky tuvo que salir de Francia a causa de una acusación de maltrato y violencia física contra su esposa. Ver: http://www.joanspicci.com/kovalevskaia/svk.pavlovsky.goncharova.htm (consultado 26/VI/2014)

28 PAVLOVSKY, I.: Ocherki sovremennoi Ispanii, 1884-1885, San Petersburgo, E. Souvorine, 1889.

29 GONZÁLEZ HERRÁN, José Manuel: "Un nihilista ruso en la España de la Restauración: Isaac Pavlovsky y sus relaciones con Galdós, Oller, Pardo Bazán y Pereda”, Anales galdosianos, Año no. 23 (1988), pp. 83-108. 
La participación de estos dos visitantes extranjeros en la escena cultural e intelectual española aporta indicios de una interacción de tipo transnacional en relación al tema del nihilismo ruso y sus personajes. Con ellos se inicia un proceso de interacción transnacional, en el que integrantes de ambas nacionalidades se asistirían mutuamente en la definición de aspectos de identidad y visiones políticas y culturales propias. Como más tarde indicaba Emilia Pardo Bazán en su conferencia "La revolución y la novela rusa", celebrada en el Ateneo de Paris en 1887, la producción cultural de España y Rusia estaban unidas por historias y sentimientos análogos. ${ }^{30}$ Cabe señalar, por ejemplo, la participación política de Leonard y Bertholet en los eventos revolucionarios de 1868 en España luego de una experiencia similar en la revolución antizarista polaca y su relación con los círculos republicanos españoles, particularmente con Emilio Castelar, autor de uno de los textos más importantes sobre Rusia, a raíz del asesinato de Alejandro II en 1881. Otra relación significativa en este panorama transnacional es la de Leonard y su mentor e ilustre periodista, Nemesio Fernández Cuesta, quien impulsó la participación de Leonard en La Gaceta de Madrid, Las Novedades y otras publicaciones progresistas de la época. ${ }^{31}$ Finalmente, la presencia de Leonard en el plantel de la Institución de Libre Enseñanza, además de su aportación al currículo de la entidad, añade otro elemento importante de interacción entre estos dos mundos aparentemente lejanos. ${ }^{32}$ En el caso de Pavlovsky, su relación con importantes escritores españoles, especialmente su amistad con Emilia Pardo Bazán, sería fundamental en la propia experiencia intelectual y política de otros grandes protagonistas de la cultura del fin de siglo español. ${ }^{33}$

\subsection{Rusia y el nihilismo en la prensa intelectual española de fin de siglo}

A pesar que Rusia y sus nihilistas eran ya objeto de discusión en los círculos intelectuales y las publicaciones más progresistas de España antes de 1881, el asesinato de Alejandro II en marzo de ese año convertiría estos temas en un elemento mediático de interés general. ${ }^{34} \mathrm{El}$ nihilismo ruso jugaría un papel protagónista en dos textos importantes publicados pocos meses después del regicidio. El primero de ellos, $L a$ Rusia contemporánea de Emilio Castelar, se enfocaba en asuntos políticos y diplomáticos entre Rusia y el resto de Europa, tales como la relación de Rusia con el imperio otomano y la situación de los Balcanes, en vísperas de la crucial conferencia de Berlín de $1881 .{ }^{35} \mathrm{El}$ autor, prominente republicano, ex-presidente de la Primera

\footnotetext{
30 PARDO BAZÁN, Emilia: La revolución y la novela en Rusia: lectura en el Ateneo de Madrid, Madrid, Publicaciones Españolas, 1961.

31 MANSBERGER AMORÓS, Roberto: “Entre la joven Polonia y el Modernismo hispánico: El Dr. Josef Leonard”, Epos. Revista de Filología, Núm. 12 (1996), pp. 473-480.

32 JIMÉNEZ LANDI, Antonio: La Institución de Libre Enseñanza y su ambiente. Tomo II: "Periodo parauniversitario", Madrid, Editorial Complutense, S.A., 1996, p. 192.

33 GONZÁLEZ ARIAS, Francisca: "La condesa, la revolución y la novela en Rusia", Bulletin Hispanique, Vol. 96, Núm. 1 (1996): 167-188.

34 LISSORGUES, Yvan: "La novela rusa en España (1886-1910)", Biblioteca Virtual Miguel de Cervantes, http://www.cervantesvirtual.com (consultado 26/VI/2014).

35 CASTELAR, Emilio: La Rusia contemporánea, Madrid, Ilustración Española y Americana, 1881. Al parecer, el texto de Castelar fue publicado originalmente en la sección "Revista extranjera" de la revista
} 
República española entre 1873 y 1874, y diputado a Cortés durante los primeros años de la Restauración, había vivido en Paris y Ginebra, donde se había relacionado con miembros de la comunidad rusa, entre los que se encontraban reconocidos revolucionarios y terroristas. ${ }^{36}$ De aquí que su tratado político estuviera aparentemente basado en la experiencia y las observaciones del autor sobre la identidad "barbárica", "asiática" y despótica de Rusia, así como sobre los males del nihilismo y la confusa naturaleza de su máxima representante, la nigiliska. ${ }^{37}$ No obstante, cabe señalar que la obra había sido publicada inicialmente en la revista del poderoso diplomático y periodista, Camilo Hurtado de Amézaga (Marqués de Riscal), por lo que el enfoque en la situación diplomática europea y la insistencia en incluir a España en la red hegemónica de potencias europeas, puede haber sido la agenda primordial del texto. ${ }^{38}$

La propuesta racista de Castelar sobre la naturaleza violenta y descabellada del absolutismo ruso también servía para disfrazar sutiles insinuaciones relacionadas con el momento político de España, para lo cual Rusia fungía de alegoría: "En el fondo... [el zarismo y el nihilismo] son uno solo y mismo partido; que la demagogia roja y la demagogia blanca se confunden y se identifican allá en igual abismo, como entre nosotros se confunden y se identifican los dos extremos de los partidos españoles, y concurren por sendas opuestas y obtienen el mismo resultado". ${ }^{39}$ En la discusión sobre la situación diplomática y la supremacía de una alianza germana en la escena política europea, Castelar se permitía intercalar una justificación para la participación de España en el escenario internacional, al tratarse, según él, de una de "las tres naciones de la historia moderna", junto con Francia e Inglaterra. ${ }^{40}$ Su tratado sugería también una semejanza entre la experiencia histórica de ambas naciones, al referirse a Rusia como "un imperio que, por su extensión y grandeza, solamente con el imperio español puede compararse en la Tierra y competir en la Historia". ${ }^{41}$

En su trabajo, Castelar hacía hincapié en la relación entre el absolutismo y el nihilismo, señalando que este último era resultado directo del propio sistema corrupto, y que a pesar de que no existía apología para los actos terroristas, tampoco podían juzgarse "los sentimientos de estos innovadores, que tienen decidida vocación al heroísmo y al martirio". ${ }^{42}$ La monarquía zarista, amarrada a un conservadurismo dictatorial y apoyada por una aristocracia anacrónica, se identificaba como el verdadero detonante de las acciones extremas de los terroristas. De aquí que las distanciadas comparaciones con la España de siglos anteriores, sirvieran para señalar de forma comparativa pero subliminal, el beneficio de un desarrollo constitucional auténtico para la institución monárquica española del momento.

\footnotetext{
Ilustración Española y Americana del 15 de mayo de 1881.

36 De acuerdo con el propio autor, su relación con la comunidad rusa en exilio databa desde un viaje anterior en 1866, durante el cual había conocido al prominente revolucionario Alexander Hertzen, el "padre" del socialismo ruso: CASTELAR, Emilio: La Rusia contemporánea..., pp. 230-31, 270.

37 CASTELAR, Emilio: La Rusia contemporánea ..., pp. 229-34, 250-55.

38 El autor no publica el nombre de la revista aunque identifica a su propietario: LISSORGUES, Yvan: "La novela rusa en España".

39 CASTELAR, Emilio: La Rusia contemporánea..., p. 87.

40 CASTELAR, Emilio: La Rusia contemporánea ..., p. 332.

41 CASTELAR, Emilio: La Rusia contemporánea ..., p. 370.

42 CASTELAR, Emilio: La Rusia contemporánea..., p. 271.
} 
Este tipo de conclusiones ambiguas y contradictorias también salpicaban el análisis del carácter de los revolucionarios rusos. En el caso de la mujer, por ejemplo, el autor resumía la historia de las nihilistas involucradas en el asesinato del zar de forma similar a la mayoría de los recuentos de la época, como si de una novela romántica se tratara: "El amor, que crea, la condujo con su incontrastable impulso a la muerte...". ${ }^{43}$ Era el desenfreno de sus sentimientos, ese "alma amante de aquella mujer enamorada", lo que había llevado a la nihiliska a consagrarse a la revolución. ${ }^{44} \mathrm{~A}$ esta explosiva mezcla de pasión, heroísmo y martirio, Castelar añadía otro elemento, una predilección por los planteamientos filosóficos alemanes, los cuales producían la mezcla letal en una mente con poca habilidad para el discernimiento: "Jóvenes educadas de esta suerte, poseídas por ideales tan radicales, exaltadas de sentimientos y de imaginación, poco dispuestas a comprender la distancia existente entre la teoría y el grado de cultura que han menester los pueblos para llegar a ciertos progresos jah! explica el tipo de la pobre [nihilista] ahorcada". ${ }^{45}$

Varios meses después del regicidio de Alejandro II de Rusia en marzo de 1881, salía también a la luz otro sobrio y detallado trabajo sobre Rusia, titulado Rusia ante Occidente: Estudio crítico del nihilismo de Joaquín Arnau é Ibáñez, respetable catedrático de la Universidad de Valencia y periodista de convicción republicana. ${ }^{46}$ Testigo y activo participante de los acontecimientos revolucionarios de 1868, Arnau é Ibáñez había también servido entonces en varios puestos políticos, convirtiéndose más tarde en catedrático en Metafísica de la Universidad de Valencia. Dentro de la comunidad intelectual del fin de siglo español se distinguió también por sus conferencias en el Ateneo de Madrid, y por su defensa de la corriente krausista en España, movimiento filosófico señalado como fundamento para la perspectiva política liberal en la España de la época.

La disertación de Arnau e Ibáñez comprobaba su extraordinario conocimiento tanto de la historia de Rusia así como de los aspectos políticos que distinguían la trayectoria despótica del zarismo. Además de un minucioso desglose de las etapas históricas del Imperio y un recuento sobre el despotismo que lo caracterizaba, el autor dedicaba varios capítulos a la evolución del movimiento revolucionario ruso y a los sucesos que habían conducido al regicidio. ${ }^{47} \mathrm{Su}$ obra también mostraba trazos del "racionalismo armónico" infundado por el krausismo, una corriente pedagógica y filosófica germana de sobresaliente protagonismo en la escena intelectual española de aquel momento. ${ }^{48}$

43 CASTELAR, Emilio: La Rusia contemporánea..., p. 362.

44 CASTELAR, Emilio: La Rusia contemporánea..., pp. 363-64.

45 CASTELAR, Emilio: La Rusia contemporánea ..., p. 365.

46 Ver: VILLANUEVA, Gabino: "Don Joaquín Arnau é Ibáñez”, VILLANUEVA, Gabino Enciso (ed.): Aragoneses ilustres, Teruel: N/A, 1890; GASCÓN y GUIMBAR, D.: "Joaquín Arnau é Ibáñez (notas para una biografía), Miscelánea Turolense 7, 10-XI-1891, pp. 110-16; FERNAN CLEMENT, Eloy: "Joaquín Arnau é Ibáñez", Gran Enciclopedia Aragonesa, Zaragoza, Unali, S.L., 1980-1982, I, pp. 159-162 (disponible en línea).

47 ARNAU e IBÁÑEZ, Joaquín: Rusia ante Occidente: Estudio crítico sobre el nihilismo, Madrid, Tipografía de El Demócrata, 1881 y Zaragoza, Tipografía de Calixto Ariño, 1882. El libro, el cual incluía también un prólogo de José de Carvajal, Ministro de Hacienda durante la primera República y Diputado a Cortes hasta 1893 , sería publicado dos veces entre 1881 y 1882, lo cual evidencia su significado dentro de la comunidad intelectual de la época.

48 El "racionalismo armónico" se refería al ideal de una humanidad unida en una "hermandad universal", lo cual requería de un plan de reforma social y educación para mejorar la condición de aquellos sectores de la 
La discusión de Arnau e Ibáñez sobre la evolución del nihilismo intercalaba muchas veces referencias anecdóticas de la experiencia española, lo cual propiciaba de forma disimulada a la reflexión. Al igual que en el texto de Castelar, las observaciones de la situación lejana junto con una sutil comparación simultánea de condiciones locales servía para enmascarar perspectivas que sobrepasaban los límites establecidos por la censura, utilizando la experiencia de Rusia como precedente o marco de referencia. La técnica del distanciamiento entrelazada con esporádicas analogías sobre España, hacían posibles las conexiones en la mente del lector. A pesar de tratarse de una discusión sobre Rusia, las ocasionales semejanzas invitaban subliminalmente a la comparación entre ambas naciones más allá del comentario particular: "[La historia rusa] no deja de afirmar el prestigio del sexo femenino dentro de las costumbres públicas. ¿Acaso no se explica en parte la especie de alteza que rodea a la mujer española en nuestro teatro antiguo, y la galantería habitual de nuestro pueblo para con sus damas, merced al hecho de haber pasado por el trono varias hembras...?". ${ }^{49}$

Al tratarse de comentarios relacionados con la situación de la mujer bajo el despotismo zarista y la falta de alternativas para la participación en el entorno público disponía, las semejanzas de Arnau e Ibáñez disponían un escenario disimulado para comentarios sobre temas y debates del momento en España, así como evidencia de las nefastas consecuencias de algunos aspectos de la modernidad. Por ejemplo, el autor parecía aludir al debate desatado en España en aquél momento en anticipación al Congreso Pedagógico de 1882 y a la decisión institucional sobre la mujer y la educación universitaria que se esperaba resultara del evento. Sobre la presencia de las mujeres en instituciones masculinas de educación superior comentaba el autor: "Lo que aquí entre nosotros es aún en parte todo un problema, pendiente de las resoluciones del Consejo de Instrucción Pública, es en Rusia hace años cuestión resuelta". No obstante, la experiencia de Rusia comprobaba el error que conllevaba el privilegio, definido por Arnau é Ibáñez con románticos y poéticos paradigmas de paternalismo:

[E]n vez de alcanzar su prestigio inefable en el seno de la familia por la práctica de las virtudes domésticas y la reforma de los corazones, se extendiera a la sociedad por el camino de la vida pública mediante el cultivo de la ciencia y prácticas profesionales que amortizan... para ahogar más tarde, las delicadezas de sensibilidad y el embeleso del amor que hacen de nuestra compañera el nuncio de ventura en el hogar.

Su perspectiva parecía también ensalzar de forma contradictoria la dedicación y el sacrificio de las nihilistas, a quienes catalogaba en términos casi religiosos de "vírgenes" totalmente entregadas a "la redención de su pueblo". .0

\footnotetext{
"civilización" ignorados y abandonados por el embate de la modernización económica y social. El enfoque del krausismo en la educación y la difusión de la cultura a los sectores populares que el krausismo puntualizaba como elementos fundamentales, hizo de esta perspectiva uno de los planteamientos más populares entre el profesorado español de fin de siglo. ). Sobre la corriente krausista y su influencia política, ver: LÓPEZ MORILLAS, Juan: The Krausist Movement and Ideological Change in Spain, 1854-1874, Cambridge (Reino Unido), Cambridge Univ. Press, 2010.

49 ARNAU e IBÁÑEZ, Rusia ante Occidente, pp. 266 -67.

50 ARNAU e IBÁÑ̃Z, Rusia ante Occidente, pp. 266-71.
} 
La experiencia de las nihilistas parecía validar en el trabajo de Arnau e Ibañez, la postura tradicional sobre la educación de la mujer, al subrayar los resultados nocivos de la enseñanza superior en la emotiva naturaleza femenina, y proponer una instrucción relativa a las responsabilidades de la mujer en la esfera doméstica. La discusión probablemente reflejaba el medio ambiente intelectual en vísperas del primer congreso pedagógico español, donde supuestamente se debía decidir si las universidades españolas estarían abiertas a estudiantes femeninas. ${ }^{51}$

El impacto perjudicial de la educación universitaria en la constitución femenina, la falta de utilidad de este tipo de enseñanza para la misión doméstica de la mujer y los peligros de una interacción social sin restricciones entre los sexos en los espacios académicos, adornaban los recuentos sobre la trayectoria de las nihilistas al terrorismo. En este caso, la universidad se convertía más bien en el lugar de reunión de una comunidad estudiantil de jóvenes aturdidos por teorías científicas dentro de una atmósfera "pseudo-liberal" y "medio ilustrada". ${ }^{52}$ No era la maldad del espíritu de los nihilistas, sino las contradicciones propias de una sociedad que se desarrollaba entre el despotismo y los ideales europeos de libertad y democracia, lo que inducía al descalabro revolucionario. La fórmula "ellos/nosotros" de una Rusia primitiva ante una Europa civilizada, que cimentaba el estereotipo nacional, también sobresalía:

[E]l nihilismo, ese fenómeno peculiar de la sociedad rusa, se ha formado y desarrollado como una consecuencia lógica del choque entre el despotismo tsarista [sic.] y los principios revolucionarios del Occidente europeo. ${ }^{53}$

\subsection{La bella y la bestia: las actitudes "modernas" y el género en los reportajes sobre el nihilismo ruso}

En una era en la que la ciencia proveía indicadores para el comportamiento y el aspecto femenino así como para las conductas aberrantes, la participación pública extremista y las actitudes de las nihilistas violentaban las nociones sobre el sexo femenino. De aquí que el análisis sobre el tema muchas veces girara alrededor de una pregunta subtextual sobre la esencia biológica de estas mujeres. En el caso particular de una de las acusadas en el regicidio, Geisa Gelfman, su avanzado estado de gestación parecía también cuestionar toda una estructura cultural en relación a la maternidad y su contexto religioso de función femenina sacrosanta. En la mayoría de los casos, el resultado del análisis resultaba todavía más confuso y incoherente que las mismas posturas de las rusas, aludiendo a las dulzuras femeninas de la nihilista a la vez que a su "fibra varonil" como aspecto positivo.

51 El congreso se llevó a cabo en 1882. A pesar de que varias resoluciones del congreso apoyaron una cierta modernización de alternativas académicas para la mujer, las universidades continuaron vedadas a estudiantes femeninas. El próximo congreso no se convocaría hasta diez años más tarde. Ver: RUIZ BERRIO, J.: “Los Congresos Pedagógicos en la Restauración”, Bordón XXXI, no. 234 (sept.-oct., 1980): 402-03; ARENAL, Concepción: La emancipación de la mujer en España, Madrid, B. Júcar, 1924; CASEMANY, M.A.: El feminismo ibérico, Barcelona, Oikos-Tau, 1970.

52 ARNAU e IBÁÑEZ, Rusia ante Occidente, pp. 260-66.

53 ARNAU e IBÁÑEZ, Rusia ante Occidente, p. 131. 
Algunas discusiones, por ejemplo, buscaban identificar a la nihilista como mujer de naturaleza femenina correcta, señalando detalles sobre su arreglo personal, su gusto por los accesorios y las características propias de su genero como su belleza, su pelo o su piel. En otras ocasiones, y de forma contradictoria, se reiteraba la fibra moral de algunas de estas mujeres, tan poco interesadas en las vanidades y superficialidades que distinguían negativamente a la mujer burguesa de la época. Muchos de los comentarios aludían, para bien o para mal, a la entereza y poder de la mujer rusa, comparando la fuerza de voluntad de éstas al carácter débil de sus compañeros. No obstante, las conclusiones subliminales parecían apuntar a una manifestación anómala de la modernización que vivía la nación, construida como composición alegórica de contrastes, en la que la bella e inocente figura se enfrentaba a una bestia monstruosa de proporciones gigantescas y capacidad insospechada para devorar a su víctima.

Particularmente fascinante resultaba el contexto sexual subliminal del fenómeno nihilista, acompañado por detalles que, más que románticos, rozaban en formatos narrativos del cotilleo morboso popular. Por ejemplo, el recuento de Arnau é Ibáñez cobraba un interesante y atrevido giro erótico al describir la relación que se entablaba entre nihilistas de ambos sexos: "La mujer casi siempre muy superior al hombre ruso en estos empeños [revolucionarios], tómale por instrumento, le subyuga, le fascina, impónese a él con la tiranía que ejerce siempre la debilidad triunfante sobre la fortaleza rendida, y guía sus pasos y encamina su voluntad y mueve su brazo con incontrastable imperio...". Nacía, pues, en la narrativa de Ibáñez una nueva y sensual Eva rusa que ofrecía al hombre, no una manzana, sino una pistola a cuyo gatillo ella misma se aferraba.

A pesar de impugnar explícitamente algunos de los comentarios de Castelar en torno a las nihilistas como "poco menos que calumnias pornocráticas", ${ }^{54}$ el autor no parecía mucho menos comedido en el tono voluptuoso de su narrativa. La calidad melodramática del tratado de Arnau é Ibáñez se tornaba aún más rebuscada al describir las peripecias de Sofía Perovskaya, líder de la banda involucrada en el regicidio:

[N]iña aún, de energías insuperables..., recorriendo los márgenes del Volga... sola y a pié, sufriendo persecución por la justicia, no era una naturaleza en que hiciera presa el placer y anidara la sensualidad. Por otra parte, si inflamada el alma de la mujer por un amor intenso llega sin esfuerzo a los arrebatos del paraíso.... [N]o es el amor del hombre, sino el amor de la humanidad... lo que mueve a estas vírgenes rusas. ${ }^{55}$

Los mensajes ambiguos y contradictorios se entrelazaban nuevamente en una narrativa de victimización en la que el acto terrorista parecía justificarse con metáforas sobre la inocencia virginal y la pasión ciega que dirigían fatídicamente la trayectoria de la regicida.

Junto con el discurso erotizado para definir las sensibilidades políticas de una terrorista de granada en mano, Arnau é Ibáñez realzaba la descripción de Perovskaya con detalles paradigmáticos sobre la apariencia femenina:

54 ARNAU e IBÁÑEZ, Rusia ante Occidente, p. 432.

55 ARNAU e IBÁÑEZ, Rusia ante Occidente, pp. 270-72. 
Ni la belleza ni las gracias fueron pródigas con Sofía Perovskaya sin que la caracterizase rasgo alguno de chocante fealdad.... Vestía con sencillez..., abultada y muy alta la frente, coronada de cabello rubio pálido..., su presencia revelaba desde luego un espíritu superior. Y así lo que le faltaba de belleza, suplíalo su ascendiente.

Por otro lado, el retrato insinuaba a la vez definiciones de género en las que los atributos de superioridad parecían relacionar a la heroína con la masculinidad, y en las que el tema de la sexualidad volvía a relucir. El autor se lanzaba también a defender la honra de la nihilista, mancillada en los periódicos: “ ¿Tentaciones la carne, aguijonazos el placer..., dominio la concupiscencia, vértigos ninfomaníacos, delirios de Mesalina en aquella naturaleza de fibra varonil, de acelerado temple, rebelde al goce, reñida con la voluptuosidad...? ¡Qué absurdo!" 56

La prensa española también reiteró los formatos narrativos de los textos de Castelar y de Arnau e Ibáñez. Por ejemplo, Sofía Perovskaya, la heroína virginal del texto de Arnau é Ibáñez, fue tema de varios artículos del diario liberal El Constitucional, establecido en Gerona para la misma época del regicidio, como órgano del Partido Liberal Dinástico de Práxedes Mateo Sagasta. De forma similar a la visión de Arnau e Ibáñez, los informes periodísticos resaltaban la entereza de esta rusa ante el verdugo en el momento de la ejecución, con prosa digna de novela: "Sofía tiene un aire resuelto. El viento ha desarreglado su peinado y sus cabellos le caen encima de la frente." Los cánones burgueses de belleza también definían la narrativa de este informe noticioso convertido en drama novelesco, en el que parecía a la vez sugerirse un juicio clasista y hasta racista en torno al ideal femenino. Por ejemplo, en un reportaje en particular, la "aristocrática" Perovskaya, "de mirada dominante", "muy inteligente", "de ojos azules y fisionomía expresiva", se contrastaba con la otra acusada, Gesya Hellman [sic.], quien se identificada como "obrera, pequeña, morena, fea y de vulgar aspecto", a pesar de que en otras publicaciones se ensalzaba su belleza. ${ }^{57}$

Los eventos en torno al asesinato de Alejandro II coincidieron también con el establecimiento de otro importante periódico de la Restauración: La Vanguardia, órgano de una fracción del entonces poderoso Partido Liberal de Barcelona (luego Partido Constitucional). ${ }^{58}$ Uno de los primeros artículos en La Vanguardia del 15 de marzo de 1881 ofrecía una opinión confusa y ambivalente, por un lado insistiendo en que "nunca podremos dejar pasar sin enérgica protesta" las acciones de los nihilistas,

56 ARNAU e IBÁÑEZ, Rusia ante Occidente, pp. 428-31. La definición corporal de género como manifestación de la sexualidad ha sido explorada en numerosos estudios recientes, como por ejemplo: LAQUER, Thomas: Making Sex: Body and Gender From the Greeks to Freud, Cambridge (Massachussetts), Harvard Univ. Press, 1990; GARB, Tamar: Bodies of Modernity: Figure and Flesh in Fin-de Siécle France, London, Thames and Hudson, 1998.

57 El Constitucional \#11, Gerona, domingo 24-04-1881, p. 3. Las alusiones a la belleza de Gelfman probablemente repetían los reportajes franceses en los que se recalcaban los datos fisionómicos. Ver, por ejemplo, los comentarios sobre las noticias de Francia en torno a las nihilistas: El Constitucional \#27, Gerona, miércoles 1-06-1881, p. 3. El propio Arnau e Ibañez mencionaba la belleza de Gelfman: ARNAU e IBÁÑEZ, Rusia ante Occidente, p. 432.

58 Para una discusión sobre el desarrollo de la prensa durante la Restauración, ver: GALLEGO, José Andrés: Revolución y restauración, 1868-1931, Madrid, Ediciones RIALP, S.A., 1982, pp. 138-42. Sobre Sagasta y su política, ver: MILÁN GARCÍA, José Ramón: La revolución entra a palacio: El liberalismo dinástico de Sagasta, 1875-1903, Logroño, Biblioteca Gonzalo de Berceo, 2000. 
y por otro aceptando "que un país que se halla regido por el despotismo...pugne y luche hasta el último extremo [sic.] por mejorar su situación política y social...".59 Días más tarde otro corto comentario establecía algunos elementos melodramáticos que colorearían los reportajes más adelante, recalcando "el carácter intransigente y apasionado del actual drama..., [y] el sentimiento de venganza personal y de odio del orden existente". ${ }^{60}$

Curioso también resulta el cuadro esbozado en un informe titulado "El nihilismo y sus causas", en el que el autor apuntaba las limitadas alternativas para la mujer fuera de la normativa tradicional de madre y esposa. Los inútiles resultados de la educación superior para la mujer se sugerían por medio del ejemplo de las nihilistas rusas: "Si se casa, está salvada... [pero habría que] compadecer al marido ya que su esposa será una mala ama de casa, que si sabe al dedillo la física y la química es incapaz de hacer el dobladillo o condimentar un guisado". No obstante, las posibilidades de una vida fuera de los confines domésticos parecían ser más apabullantes:

Si no se casa, está fatalmente destinada a la prostitución o al nihilismo. Como es generalmente fea y desprovista de elegancia, la prostitución no le aprovecha gran cosa y entonces se hace la cómplice de los fabricantes de bombas..., y dará voluntariamente la vida, esa vida desgraciada que de nada le sirve, para derribar una sociedad en la que no tiene lugar que ocupar. ${ }^{61}$

Años más tarde, el nihilismo ruso aun sobresalía como alegoría de pasión y drama en relatos informativos en los que la mujer dominaba la trama. Una historia de la vida real reproducida en La Vanguardia relataba un auténtico culebrón protagonizado por Sergei Podolinski, médico ruso residente en Francia y su esposa Natalia, quien apoyaba la causa revolucionaria nihilista. El espíritu independiente desenfrenado de la mujer y la debilidad del hombre ante esa libertad sin controles, resultaban nuevamente motivo e impulso para la calamidad y la tragedia. Entrelazados en el informe se incluían ingredientes del estereotipo de la apasionada nihilista rusa que Natalia representaba, con su "ardiente naturaleza" y su "necesidad de emociones fuertes". El toque de erotismo con tono de cotilleo morboso también se sugería en los detalles de la noticia, al apuntar que Natalia había abandonado al marido y a sus dos hijos por el joven asistente ruso de su marido, no sin antes explicarle al médico su deseo de experimentar la libertad plena y pedirle su permiso para tener amantes que según ella "pudieran ser útiles a la causa". Poco después morían sus dos hijos y el marido perdía la cabeza, por lo que sería ingresado en un asilo por su madre.

El informe no proporcionaba un desenlace para la historia, aunque mencionaba que Natalia había pedido a las autoridades francesas que obligaran a la madre de Sergei a regresar a éste a su hogar para cuidarlo. ${ }^{62} \mathrm{Al}$ parecer, el destino había logrado regresar

59 "Lo de Rusia", La Vanguardia, Barcelona, 15-03-1881, p. 6.

60 La Vanguardia, Barcelona, 19-03-1881, pp. 2-5.

61 La Vanguardia, Barcelona, 3-04-1881, pp. 6-7.

62 Algunas obras identifican a Podolinski como aristócrata y populista, así como científico sobresaliente y pionero en el desarrollo de la teoría termodinámica. Ver, por ejemplo: MARTíNEZ ALLIER, Juan: Ecological Economics, Oxford (R.U.), Blackwell Publishing, 1990; PASSET, René: L'Illusion du Néo-Libéralisme, Paris, Fayard, p. 38. Al parecer, pasó sus últimos años en su casa, por lo que la petición de Natalia parece haber 
a esta mujer a su lugar correspondiente. Por convicción propia, Natalia asumía finalmente su papel de esposa. Como nota al calce para la historia, el artículo señalaba que por su fanatismo ciego, su ardiente fe y su lucha por un ideal, no era de sorprender que los nihilistas rusos se hubieran convertido en "una leyenda moderna". ${ }^{63}$

\section{Comentarios finales}

Esta investigación señala la forma en que asuntos extranjeros pueden haber servido de plataforma para la discusión de temas nacionales y locales, subliminalmente disfrazados en una narrativa entre líneas. Por ejemplo, en el plano político y cultural, se trataba de una comparación subliminal entre una Rusia "atrasada" y "despótica", y una España "europea" y "occidental", como sugería el título de Arnau e Ibáñez. Por otra parte, el estudio además indica que las discusiones en una prensa identificada con el liberalismo político, pueden haber servido para reforzar una perspectiva conservadora en torno a temas relacionados con el fenómeno modernista, tanto en términos políticos, así como en el contexto social y cultural. El trabajo aporta evidencia concreta de las contradicciones que se suscitaron en la construcción de visiones culturales españolas de fin de siglo, las cuales, según han apuntado algunos historiadores, parecían divagar no sólo entre el liberalismo y el conservadurismo, sino entre una lealtad a la tradición y un compromiso con la modernidad. ${ }^{64}$ En términos sociales, por ejemplo, la discusión parecía corroborar solapadamente, los nefastos resultados de las actitudes liberales desmedidas en relación al género, al subrayar el papel protagonista de las revolucionarias rusas en el movimiento nihilista. La experiencia de las nihilistas ofrecía además una oportunidad concreta pero distanciada para abordar el tema del acceso de la mujer a las universidades, destacando la siniestra correlación entre la educación universitaria y una postura transgresiva en la mujer.

La discusión en la prensa intelectual sobre el radicalismo ruso y las nihilistas puntualiza además la forma en que ciertos estereotipos de alto contenido literario y melodramático fueron también encontrando un espacio en los entornos cultivados del país. A pesar de estar fundamentados en la realidad, más allá del ámbito ilusorio de la literatura y el teatro, el carácter contradictorio de los mensajes, elogiosos a la vez que detractores, permitían un espacio para la reflexión sobre temas del momento, tales como el género y su naturaleza emocional y psicológica. En este caso, el espíritu inquebrantable de las nihilistas rusas daba indicios de un temperamento femenino particular, lo cual a la vez comprobaba la veracidad del estereotipo romántico convertido

sido concedida. Por otro lado, a Natalia (Akimova Andreeva) también se le relaciona con otra nihilista, Olga Lubatovich, con quien participó en algunos actos terroristas, según la revista rusa Byloe de 1909. Para una corta biografía de Podolinski, ver: “A propos: Serhii Podolynsky (1850-1891), Histoire et Cultures de l'Europe et de l'Est, http://www.aleph99.org/chee/podo.html (consultado 21/VI/2014).

63 "Fanatismo nihilista", La Vanguardia, Barcelona, 26-11-1885, p. 5.

64 Ibid, pp. 67-70; LITVAK, Lily: España 1900. Modernismo, anarquismo y fin de siglo, Barcelona, Anthropos, 1990. Litvak ofrece un panorama español para el concepto de la necesidad de unificar las complejidades culturales, sociales y políticas en una visión "nacional" a la vez que pluralista, moldeado originalmente por Carl Schorske: SCHORSKE, Carl: Fin-de-siècle Vienna: Politics and Culture, New York, Vintage Books, 1980. 
en realidad idealizada. De aquí que la sensualidad sirviera también muchas veces de denominador común en este tipo de narrativa, al proponer el nivel emotivo, pasional e incoherente de la naturaleza femenina enfrentada a los asuntos de la razón. En este sentido los textos aportan una muestra de contextualización histórica y precedente para la construcción de paradigmas contradictorios de género, convertidos en una "realidad" concreta y única.

La discusión del nihilismo en la prensa ilustrada y los periódicos españoles también sugiere un espacio intelectual mucho más inclusivo socialmente, al integrar una variedad de géneros narrativos que van desde el empirismo sofisticado y académico, hasta el meloso romanticismo erotizado de la novela sensacionalista, favorita entre las clases más populares. En ciertos casos, el reportaje también proporcionaba un lugar para formatos discursivos de tono aun más atrevidos que los del folletín, al incorporar actitudes más afines con el cotilleo de toque morboso, entre macabro y erótico. Se trataba de una narrativa de aspectos y preferencias representativas de la diversidad social de la España de fin de siglo, representada tanto por el estrato acomodado y educado así como por el del lector de las series de literatura por entregas. Es posible que en su afán "democratizador" e inclusivo, la prensa liberal intentara llegar a una población más amplia por medio de un discurso de tono popular, en el que se entremezclaban temas intelectuales con la aventura, ejecuciones y asesinos, héroes y villanos, y virginales ninfas de la modernidad. ${ }^{65}$ Como en el caso de otros modos culturales masivos españoles, posiblemente se trataba de una "confusa interacción entre la alta cultura y la popular" para promover una visión subliminal de unidad "nacional" y pluralista, por medio de un formato emotivo, melodramático y sensacionalista con el que todos podían identificarse. ${ }^{66}$ Más importante aun resulta el hecho de que las contradicciones suscitadas por los cambios sociales, políticos u económicos se resolverían en un plano transnacional, en el que la realidad política y social de Rusia servía de evidencia y experiencia. Como indica el caso de la construcción del nihilismo ruso en la prensa liberal española, las visiones normativas autóctonas en torno a temas tales como identidad, género y nación, se fundamentarían en propuestas relativas a la experiencia del "otro" extranjero y distante, aunque no siempre diferente y ajeno.

La forma en que se desarrolla el análisis de los eventos y se estructuran sus personajes como estereotipos, sugiere una fusión de esferas culturales que, por lo regular, se entienden aisladas. En este caso se trata de una interacción entre el medioambiente intelectual en donde se discuten los acontecimientos de la realidad, la cultura popular que salpica los relatos de morbo sugerente y cotilleo pueblerino, y el espacio literario

65 Para esta misma época se comienza a publicar en España, un tipo de literatura popular en ser conocida como "novelas por entrega" o folletín. De acuerdo con algunos historiadores, este género ayudó de forma notable a moldear visiones culturales y hasta revolucinarias entre las clases populares en Rusia, al enfocarse en estereotipos representativos del bien y el mal, y la justicia y la injusticia, utilizando también prototipos femeninos erotizados representativos de esclavitud, sometimiento y dominación. Ver, por ejemplo, el análisis de la literatura del folletín (liubok) en la Rusia de fin de siglo: BROOKS, Jeffrey: When Russia Learned To Read: Literacy and Popular Literature, 1861-1917, Chicago, Northwestern University Press, 2003.

66 LABANYI, Jo: "Horror, Spectacle, and Nation-formation: Historical Painting in Late Nineteenth Century Spain", en LABANYI, Jo (ed.): Hold That Pose!: Visual Culture in the Late Nineteenth Century Spanish Periodical, Philadelphia, Pennsylvania Univerity Press, 2008, p. 70. 
de melodrama y romanticismo. Al igual que las nuevas perspectivas sobre modernidad y género reconocen una interacción mucho más activa entre el espacio público y el privado, es posible que en un futuro cercano podamos redefinir históricamente el texto periodístico o académico como manifestaciones de la experiencia humana más allá de su contexto intelectual y tradicional, aportando así otro prisma por el cual analizar la experiencia cultural decimonónica.

\section{Referencias bibliográficas}

ABRAMS, Lynn: The Making of Modern Woman: Europe, 1789-1918, New York, Longman, 2002.

ARENAL, Concepción: La emancipación de la mujer en España, Madrid, B. Júcar, 1924. ARKINSTALL, Chrisitine: "Configuring the Nation in the Fin-de-siécle Spain: Rosario de Acuña's La voz de la Patria," Hispanic Review 74, no. 3 (Summer 2006), pp. 301-18.

ARNAU e IBÁÑEZ, Joaquín: Rusia ante Occidente: Estudio crítico sobre el nihilismo, Madrid, Tipografía de El Demócrata, 1881 y Zaragoza, Tipografía de Calixto Ariño, 1882.

AYALA ARACIL, María de los Ángeles: “Ángela Grassi: Del Romanticismo al Dualismo Moral", Anales de literatura español 18 (2005): 53-64.

AYNES, Jean René y SEBASTIÁN, Javier Fernández (eds.): La imagen de Francia en España (1808-1850), Bilbao, Universidad del País Vasco, 1997.

BALLARÍN, Pilar: La educación de las mujeres en la España contemporánea. Siglos XIX y XX, Madrid, Síntesis, 2001.

BROOKS, Jeffrey: When Russia Learned To Read: Literacy and Popular Literature, 1861-1917, Chicago, Northwestern University Press, 2003.

BURLEIGH, Michael: Blood and Rage: A Cultural History of Terrorism, New York, Harper Collins Publishers, 2008.

CAINE, Barbara y SLUGA, Brenda (eds.): Gendering European History, 1780-1920, New York, Continium International Publishing, 2000.

CASEMANY, M.A.: El feminismo ibérico, Barcelona, Oikos-Tau, 1970.

CASTELAR, Emilio: La Rusia contemporánea, Madrid, Ilustración Española y Americana, 1881.

CHAMBERLAIN, Vernon A. y WEINER, Jack: "A Russian View in 1884-1885 of Three Spanish Writers: Galdós, Pardo Bazán y Pereda," Anales galdosianos, Año XIX (1984), pp. 108-119.

CHARNON-DEUTSCH, Lou: Fictions of the Feminine in Nineteenth Century Spain, Philadelphia, Pennsylvania Univ. Press, 1999.

COLIN, Vera: “A Note on Tolstoy and Galdós” Anales galdosianos, Año 2 (1967), pp. 155-68; 
DE MADARIAGA, Isabel: "Spain and the Decembrists," European Review 3, no. 2 (1973), pp. 141-156.

DODOLEV, M.A.: "Russia and the Spanish Revolution, 1820-1823," Russian Studies in History, Vol. 8, no. 3 (Winter 1969-70).

EPPS, Bradley S. y CIFUENTES FERNÁNDEZ, Luis (eds.): Beyond Spain, Lewisburg (Pennsylvania), Bucknell Univ. Press, 2005.

ETREROS, Mercedes: "Influjo de la narrativa rusa en Doña Emilia Pardo Bazán: El ejemplo de La Piedra Angular," Anales de la literatura española 9 (1993), pp. 31-44.

FELSKI, Rita: The Gender of Modernity, Cambridge (Massachusetts), Harvard University Press, 1995.

FERNAN CLEMENT, Eloy: “Joaquín Arnau é Ibáñez”, Gran Enciclopedia Aragonesa, Zaragoza, Unali, S.L., 1980-1982, I, pp. 159-162 (disponible en línea).

FERNÁNDEZ SEBASTIÁN, Javier y CAPELLÁN DE MIGUEL, Gonzalo: "The Notion of Modernity in 19th Century Spain: An Example of Conceptual History", European Journal of Political Theory, Vol. 3, no. 4 (October, 2004), pp. 393-410.

FLECHA GARCÍA, Consuelo: Las primeras universitarias en España, Madrid, Narcea, 1996.

Las mujeres en la legislación educativa española. Enseñanza primaria y normal en los siglos XVIII y XIX, Sevilla, Gihus, 1997.

FOX, E. Inman: La invención de España: Nacionalismo liberal e identidad nacional, Madrid, Cátedra, 1998.

FUCHS, Rachel y THOMPSON, Victoria (eds.): Women in Nineteenth Century Europe, New York, Palgrave Macmillan, 2005.

GALLEGO, José Andrés: Revolución y restauración, 1868-1931, Madrid, Ediciones RIALP, S.A., 1982.

GARB, Tamar: Bodies of Modernity: Figure and Flesh in Fin-de Siécle France, London, Thames and Hudson, 1998.

GASCÓN y GUIMBAR, D.: “Joaquín Arnau é Ibáñez (notas para una biografía), Miscelánea Turolense 7, 10-XI-1891, pp. 110-16.

GONZÁLEZ HERRÁN, José Manuel: "Un nihilista ruso en la España de la Restauración: Isaac Pavlovsky y sus relaciones con Galdós, Oller, Pardo Bazán y Pereda", Anales galdosianos, Año no. 23 (1988), pp. 83-108.

GUIDOTTI-HERNÁNDEZ, Nicole: Unspeakable Violence: Remapping US and Mexican National Imaginaries, Durham, Duke University Press, 2011.

HARTMAN, Mary S.: The Household and the Making of History: A Subversive View of the Western Past, New York, Cambridge Univ. Press, 2004.

HAUNER, Milan, "Terrorism and Heroism: The Assassination of Reinhard Heydrich," World Policy Journal 24, no. 2 (Summer, 2007), pp. 85-89.

HENEGHAN, Dorothea: "Shopping Angels: Fashion, Gender, and Modernity in Galdós' La de Bringas," Dissidences: Vol. 1, Iss. 2 (2006). 
HERAS, Pilar y VILANOU, Conrad (eds.): Pedagogía amb veu de dones, Barcelona, Facultat de Pedagogía, 1999.

HSIAO, Li Chun (ed.): This Shipwreck of Fragments: Historical Memory, Imaginary Identities, and Postcolonial Geography in Caribbean Culture and Literature, Newcastle upon Tyne, Cambridge Scholars Publishing, 2009.

JOHNSON, Robert: Gender and Nation in the Spanish Modernist Novel, Nashville, Vanderbilt University Press, 2003.

KIRPATRICK, Susan: Las Románticas: Women Writers and Subjectivity in Spain, 1835-1850, Berkeley, University of California Press, 1989.

LABANYI, Jo: Constructing Identity in Contemporary Spain: Theoretical Debates and Cultural Practice, Oxford, (Reino Unido), Oxford Univ. Press, 2002.

LABANYI, Jo (ed.): Hold That Pose!: Visual Culture in the Late Nineteenth Century Spanish Periodical, Philadelphia, Pennsylvania University Press, 2008.

LAQUER, Thomas: Making Sex: Body and Gender From the Greeks to Freud, Cambridge (Massachussetts), Harvard University Press, 1990.

LEMA, María: "El morbo: ¿sólo una atracción malsana? Análisis de una conceptualización en dos culturas", Romanica.doc, Czasopismo doktorantów Instytutis Filologii Romanskiej: num. 1(2), 2011, pp. 1-12, disponible en línea: www.romdoc. amu.edu.pl/lema.html

LITVAK, Lily: España 1900. Modernismo, anarquismo y fin de siglo, Barcelona, Anthropos, 1990.

LÓPEZ MORILLAS, Juan: The Krausist Movement and Ideological Change in Spain, 1854-1874, Cambridge (Reino Unido), Cambridge Univ. Press, 2010.

LOREÉ ENDERS, Victoria y RADCLIFF, Pamela Beth: Constructing Spanish Womanhood: Female Identity in Modern Spain, Albany, State Univ. of New York, 1999.

MARKS, Steven G.: How Russia Shaped the Modern World: From Art to Anti-Semitism, Ballet to Bolshevism, Princeton (New Jersey), Princeton University Press, 2004.

MAYORAL, Mariana: Escritoras Románticas Españolas, Madrid, Fundación Banco Exterior, 1990.

MILÁN GARCÍA, José Ramón: La revolución entra a palacio: El liberalismo dinástico de Sagasta, 1875-1903, Logroño, Biblioteca Gonzalo de Berceo, 2000.

MUNSON, Elizabeth: "Walking on the Periphery: Gender and the Discourse of Modernity," Journal of Social History 36, no. 1 (2002), pp. 63-75.

NECHKINA, M.V.: "Revoliutsiia na podobie ispanskoi," Katorga i ssylka, no. 10 (1931), pp. 3-40.

OSBORNE, R.E.: "Emilia Pardo Bazán y la novela rusa," Revista Hispánica Moderna 20, no. 4 (Oct. 1954), pp. 273-281.

PAVLOVSKY, I.: Ocherki sovremennoi Ispanii, 1884-1885, San Petersburgo, E. Souvorine, 1889. 
PERCEVAL, José María: Nacionalismos, xenofobia y racismo en la comunicación, Madrid, Paidos Ibérica, 1995.

PETTISON, Walter Thomas: El naturalismo español: Historia externa de un movimiento literario, Madrid: Gredos, 1965.

RATOW-EDLING, Susanna: "The Decembrist Movement and the Spanish Constitution of 1812," Historia Constitucional, Revista electrónica, no. 13 (2012), pp. 143161, www.historiaconstitucional.com, acceso digital por medio de: http://www. ucrs.uu.se/digitalAssets/125/125466_susannarabowedlingdecembristmovement. pdf

RUIZ BERRIO, J.: “Los Congresos Pedagógicos en la Restauración”, Bordón XXXI, no. 234 (sept.-oct., 1980): 402-403.

SÁNCHEZ LLAMA, Íñigo: Galería de escritoras isabelinas: La prensa periódica entre 1833 y 1895, Valencia: Universitat de València, 2000.

SAN ROMÁN GAGO, Sonsoles: Las primeras maestras. Los orígenes del proceso de feminización docente en España, Barcelona, Ariel, 1998.

SILJAK, Ana: Angel of Vengence: The Girl Who Shot the Governor of St. Petersburg and Sparked the Age of Assassination, New York, St. Martin's Press, 2008.

STITES, Richard: "Decembrists with a Spanish Accent," Kritika: Explorations in Russian and Eurasian History, 12, no. 1 (Winter 2011), pp. 5-23.

URBANSKI, Edmund Stephen: "El Doctor José Leonard: El maestro de Rubén Darío y sus actividades culturales Franco-Españolas-Latinoamericanas," Anuario de Estudios Centroamericanos, no. 1 (1974): 33-46.

VAILLO, Carlos: "La novela rusa en España," Ínsula: Revista de letras y ciencias humanas, No. 498-499 (1988), p. 12.

VILLANUEVA, Gabino Enciso (ed.): Aragoneses ilustres, Teruel: N/A, 1890.

WHISNANT, David E.: "Ruben Dario as a Focal Cultural Figure in Nicaragua: The Ideological Uses of Cultural Capital," Latin American Research Review, 27, no. 3 (1992), pp. 7-49. 